SANTANA, Y.A.G. et al. Degradabilidade ruminal in situ de dietas volumosas para ruminantes constituídas pelos fenos de capim-tifton 85 e de leucena. PUBVET, Londrina, V. 6, N. 10, Ed. 197, Art. 1322, 2012.

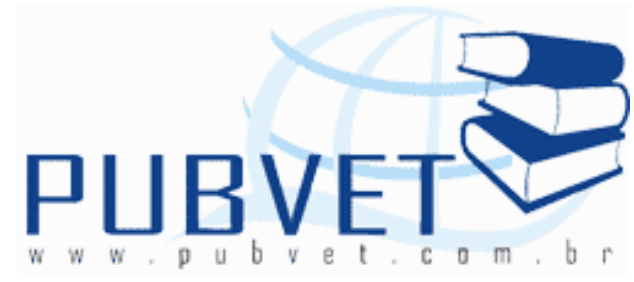

PUBVET, Publicações em Medicina Veterinária e Zootecnia.

\title{
Degradabilidade ruminal in situ de dietas volumosas para ruminantes constituídas pelos fenos de capim-tifton 85 e de leucena
}

Yânez André Gomes Santana ${ }^{1}$, Arnaud Azevêdo Alves ${ }^{2}$, Miguel Arcanjo Moreira Filho $^{1}$, Cícero Fortes de Cerqueira Neto ${ }^{3}$, Melina da Conceição Macêdo da Silva ${ }^{1}$

${ }^{1}$ Programa de Pós-Graduação em Ciência animal da Universidade Federal do Piauí

${ }^{2}$ Universidade Federal do Piauí.

${ }^{3}$ Universidade Federal do Piauí, Bolsista PIBIC/CNPq.

\section{Resumo}

Avaliou-se o valor nutritivo, quanto à composição bromatológica e degradação in situ da matéria seca, proteína bruta e fibra em detergente neutro. Adotou-se o delineamento inteiramente casualizado (DIC), fatorial $2 \times 2$ (feno de capimTifton 8528 dias $+20 \%$ de feno de leucena [FT28d+20L], feno de capimTifton 8528 dias $+40 \%$ de feno de leucena [FT28d+40L], feno de capimTifton 85 42dias $+20 \%$ de feno de leucena [FT42d+20L], feno de capim-Tifton 8542 dias $+40 \%$ de feno de leucena [FT42d+40L]) em parcelas subdivididas nos tempos $6,24,72 \mathrm{~h}$. O feno de capim-Tifton 85 com duas idades de rebrota x Níveis do feno de leucena (20 e 40\% da MS) resultou em taxa de degradação de $c$ da MS superior a 3,0\%/h, a fração solúvel da FDN aumentou com nível de $40 \%$ feno de leucena, com grande participação da fração $b$, com taxa de degradação $(c)$ superior a 2,0\%/h. A MS do feno de leucena, apresentou-se 
SANTANA, Y.A.G. et al. Degradabilidade ruminal in situ de dietas volumosas para ruminantes constituídas pelos fenos de capim-tifton 85 e de leucena. PUBVET, Londrina, V. 6, N. 10, Ed. 197, Art. 1322, 2012.

muito solúvel (fração $a=33,59 \%$ ) e pouco degradável in situ (fração $b=32,59 \%)$, no entanto, as estimativas de degradação potencial às taxas de passagem 2, 5 e $8 \% \mathrm{~h}^{-1}$, para os níveis de consumo alimentar baixo, médio e alto, de 60,$07 ; 54,25$ e 50,53\%, respectivamente. O feno de leucena promove aumento no teor de proteina bruta, incrementando o teor de $\mathrm{PB}$, a degradabilidade in situ e a cinética de degradação da MS, PB e FDN com 40\% do feno de leucena.

Termos para indexação: composição bromatológica, degradação in situ, Leucaena leucocephala.

\section{Rumen degradability in situ forage diet for Ruminants Formed by Hays Tifton 85 and Leucena}

\section{Summary}

We evaluated the nutritional value, as the chemical composition and in situ degradation of dry matter, crude protein and neutral detergent fiber. We adopted a completely randomized design (CRD), a $2 \times 2$ (hay Tifton 28 days 85 $+20 \%$ hay leucaena [FT28d +20 L], hay Tifton 28 days $85+40 \%$ hay Leucaena [FT28d +40 L], hay Tifton 42 days $85+20 \%$ hay leucaena [FT42d +20 L], hay Tifton 42 days $85+40 \%$ Leucaena hay [FT42d +40 L]) in split plot at $6,24,72 \mathrm{~h}$. Hay Tifton 85 with two levels of regrowth $x$ leucaena hay (20 and $40 \%$ of DM) resulted in degradation rate of DM c exceeding $3.0 \%$ / $h$, the soluble fraction of NDF increased level with $40 \%$ Leucaena hay, with the participation of fraction $b$, with the rate of degradation (c) exceeding $2.0 \% / \mathrm{h}$. The DM of Leucaena hay, were much soluble fraction $(a=33.59 \%)$ and little in situ degradable fraction ( $b=32.59 \%$ ), however, estimates of potential degradation rates of passage 2,5 and $8 \% \mathrm{~h}-1$ for the levels of food consumption low, medium and high of $60.07,54.25$ and $50.53 \%$ respectively. The Leucaena hay promotes an increase in protein content, increasing the CP 
SANTANA, Y.A.G. et al. Degradabilidade ruminal in situ de dietas volumosas para ruminantes constituídas pelos fenos de capim-tifton 85 e de leucena. PUBVET, Londrina, V. 6, N. 10, Ed. 197, Art. 1322, 2012.

content, the in situ and the kinetics of degradation of DM, CP, and $40 \%$ Leucaena hay.

Index terms: chemical composition, degradation in situ, Leucaena leucocephala

\section{Introdução}

A região Nordeste do Brasil é caracterizada por duas estações bem definidas, uma seca e outra chuvosa, o que implica em estacionalidade na produção de forragem e, consequentemente, na redução na produtividade do rebanho. Visando contornar este efeito, é importante a conservação de volumosos disponíveis durante o período chuvoso, os quais podem ser conservados sob a forma de feno ou silagem e utilizados para suplementar o rebanho no período de escassez de forragem, visando à sustentabilidade da produção animal.

Devido às forrageiras convencionais apresentarem comprometimento da qualidade, quanto ao consumo e digestibilidade, associado à sazonalidade de produção, em algumas áreas do Brasil já se incorporou aos sistemas produtivos o uso de componentes vegetativos (folhagem) de leguminosas exóticas e gramíneas, com destaque para a leucena (Leucaena leucocephala (Lam.) De Wit.) e capim-Tifton 85 (Cynodon SSP).

O feno de leucena, com elevado conteúdo de proteína bruta, principalmente proteína verdadeira e nitrogênio não protéico, com degradabilidade da proteína bruta bastante alta (Lopez, 2006), se fazendo necessário o desenvolvimento de estudos, sob diferentes formas de conservação, incentivando-se assim a utilização na alimentação de ruminantes, o que segundo, no Brasil ainda é pouco aproveitado de forma racional (Perez 1999).

O conhecimento da degradabilidade ruminal das diferentes frações dos alimentos e, especialmente, da proteína é de grande importância para os ruminantes que são atendidos pelos aminoácidos absorvidos no intestino 
SANTANA, Y.A.G. et al. Degradabilidade ruminal in situ de dietas volumosas para ruminantes constituídas pelos fenos de capim-tifton 85 e de leucena. PUBVET, Londrina, V. 6, N. 10, Ed. 197, Art. 1322, 2012.

delgado, sendo estes provenientes da proteína microbiana e dietética não degradada no rúmen (Tonani et al., 2001). Além disso, permite identificar fatores que afetam o consumo voluntário de forragens, como o grau de maturidade, a relação caule-folha e a forma de processamento, sendo fundamental o conhecimento da degradabilidade da proteína para se atender exigências nutricionais. (Ladeira et al., 2001).

A técnica de sacos de náilon, mediante incubação de sacos no rúmen de animais fistulados é útil para se determinar a degradabilidade de diferentes frações, como MS, $\mathrm{N}$ e fibra, e para se comparar diferentes produtos, sendo a mais utilizada para se avaliar a degradação protéica ruminal, devido a facilidade de padronização desta técnica entre laboratórios (Nocek, 1988).

Neste contexto, esta pesquisa foi realizada com o objetivo de avaliar dietas volumosas constituídas por duas proporções do feno de capim-Tifton 85 processado em dois estádios vegetativos com o feno de leucena para ruminantes, sobre o valor nutritivo, quanto à composição bromatológica e degradação in situ da matéria seca, proteína bruta e fibra em detergente neutro.

\section{Material e Métodos}

Este experimento foi conduzido no Departamento de Zootecnia (DZO) do Centro de Ciências Agrárias (CCA) da Universidade Federal do Piauí (UFPI), em Teresina-PI, localizado em latitude $05^{\circ} 02^{\prime} 28.17^{\prime \prime}$ Sul, longitude $42^{\circ} 46^{\prime} 56.99^{\prime \prime} \mathrm{e}$ altitude 71,3 m, visando determinação da degradabilidade in situ da MS, PB e FDN do feno de capim-Tifton 85 processados aos 28 e 42 dias após rebrota do feno de leucena processado aos 40 dias e das associações destes ingredientes (dietas experimentais), sendo esta apresentada na Tabela 1, foi utilizado um bovino mestiço da raça Guzerá canulado no rúmen, com peso vivo $700 \mathrm{~kg}$. 
SANTANA, Y.A.G. et al. Degradabilidade ruminal in situ de dietas volumosas para ruminantes constituídas pelos fenos de capim-tifton 85 e de leucena. PUBVET, Londrina, V. 6, N. 10, Ed. 197, Art. 1322, 2012.

Tabela 1. Composição bromatológica das dietas experimentais e dos fenos de leucena (FL) e de capim-Tifton 85 processado aos 28 (FT28d) e 42 (FT42d) dias de rebrota

\begin{tabular}{|c|c|c|c|c|c|c|c|}
\hline \multirow{3}{*}{ Constituintes } & $\mathrm{FT2}$ & & $\mathrm{FT}<$ & $42 d$ & \multirow{3}{*}{$\mathrm{FL}$} & \multirow{3}{*}{ FT28d } & \multirow{3}{*}{ FT42d } \\
\hline & \multicolumn{4}{|c|}{ Níveis de FL (\%) } & & & \\
\hline & 20 & 40 & 20 & 40 & & & \\
\hline $\begin{array}{l}\text { Matéria seca } \\
\text { Com base na MS }\end{array}$ & 84,98 & 84,46 & 83,78 & 83,56 & 82,90 & 85,50 & 84,00 \\
\hline Proteína bruta & 12,69 & 14,41 & 11,32 & 13,39 & 19,60 & 10,96 & 9,25 \\
\hline $\begin{array}{l}\text { Fibra em detergente } \\
\text { neutro }\end{array}$ & 77,61 & 75,37 & 79,42 & 76,73 & 68,65 & 79,85 & 82,11 \\
\hline $\begin{array}{l}\text { Fibra em detergente } \\
\text { ácido }\end{array}$ & 41,62 & 43,65 & 42,53 & 44,34 & 49,76 & 39,58 & 40,29 \\
\hline Cinza & 6,50 & 6,28 & 6,90 & 6,57 & 5,60 & 6,73 & 7,22 \\
\hline $\begin{array}{l}\text { Energia Bruta } \\
\text { (Mcal/kg) }\end{array}$ & 4,37 & 4,33 & 4,40 & 4,35 & 4,20 & 4,42 & 4,45 \\
\hline
\end{tabular}

Durante o período experimental, incluindo o período de adaptação de sete dias, o bovino recebeu dieta total para mantença, composta por volumoso e concentrado, com relação volumoso:concentrado 80:20. Foi formulada a dieta visando atender às recomendações do NRC (2001) para novilhos, em mantença, fornecida em duas refeições (às 8 e 16 h), além de água à vontade. A degradabilidade in situ foi avaliada utilizando-se sacos de náilon medindo $12 \times 8 \mathrm{~cm}$, com porosidade $50 \mu \mathrm{m}$, contendo aproximadamente $4 \mathrm{~g}$ de amostra (Tomich e Sampaio, 2004).

Os sacos com amostras foram incubados através da cânula ruminal, por onde passou um fio guia que, em uma extremidade, sustentou os sacos de náilon com as amostras, na extremidade externa, foi acondicionado um suporte para evitar que o conjunto suspenso pelo fio guia permaneça imerso 
SANTANA, Y.A.G. et al. Degradabilidade ruminal in situ de dietas volumosas para ruminantes constituídas pelos fenos de capim-tifton 85 e de leucena. PUBVET, Londrina, V. 6, N. 10, Ed. 197, Art. 1322, 2012.

no rúmen. O conjunto foi ancorado por um peso de $500 \mathrm{~g}$ para que o material testado entre em contato com a microbiota ruminal (Uden, 1984).

Foram adotados os períodos de incubação 6, 24 e 72 h. Após o período de incubação, os sacos desincubados foram acondicionados em recipiente com gelo, para cessar o processo fermentativo, e em seguida foram, lavados em máquina de lavar até a água se apresentar límpida (Uden, 1984). Em seguida foram pré-secos em estufa de circulação forçada de ar a $55^{\circ} \mathrm{C}$ por 72 horas, para análises bromatológicas de MS, PB e FDN.

Os parâmetros de degradação in situ $(a, b$ e $c)$ e a degradabilidade potencial da MS, PB e FDN, foram estimados pelo modelo proposto por Sampaio (1995), a partir de simplificação do modelo exponencial proposto por Ørskov e McDonald (1979), expresso por DP $=$ A - B.e $e^{-c . t}$, em que, DP = percentagem real do nutriente degradado após $t$ horas de incubação no rúmen; $A=$ potencial máximo de degradação do material no saco de náilon (assíntota); $\mathrm{B}=$ fração potencialmente degradável do material que permanece no saco de náilon após o tempo zero; c = taxa de degradação da fração remanescente no saco de náilon após tempo zero; $t$ = tempo de incubação.

A degradabilidade efetiva (DE) da $M S, P B$ e FDN no rúmen foram estimadas considerando-se as taxas de passagem 2, 5 e 8\%/h (AFRC, 1993), do feno de capim-Tifton 85 processados aos 28 e 42 dias após rebrota do feno de leucena processado aos 40 dias e das associações destes ingredientes (dietas experimentais), utilizando-se a equação proposta por Ørskov e McDonald (1979), DE = a + [(b c) / $(c+k)]$, em que, DE = Degradação efetiva; $a=$ fração solúvel, rapidamente degradada; $b=$ fração insolúvel, lentamente degradada; $c=$ taxa fracional de degradação de $b ; k=$ taxa de passagem.

Para avaliação da degradação, foram realizadas estatísticas descritivas para média da MS, PB e FDN e desvio padrão, segundo o procedimento para médias (PROC MEANS) do logiciário estatístico SAS (2000), enquanto os parâmetros não lineares $a, b$ e $c$ foram obtidos pela equação exponencial, 
SANTANA, Y.A.G. et al. Degradabilidade ruminal in situ de dietas volumosas para ruminantes constituídas pelos fenos de capim-tifton 85 e de leucena. PUBVET, Londrina, V. 6, N. 10, Ed. 197, Art. 1322, 2012.

proposta por Ørskov e McDonald (1979), e determinados utilizando-se o método de Gauss-Newton, através da fase interativa do Procedimento para Modelos Não Lineares (PROC NLIN) do logiciário estatístico SAS (2000), adotando um delineamento inteiramente ao acaso, em esquema de fatorial $2 \mathrm{x}$ 2 (feno de capim-Tifton 8528 dias $+20 \%$ de feno de leucena [FT28d+20L], feno de capim-Tifton 8528 dias $+40 \%$ de feno de leucena [FT28d+40L], feno de capim-Tifton 85 42dias $+20 \%$ de feno de leucena [FT42d+20L], feno de capim-Tifton 8542 dias $+40 \%$ de feno de leucena [FT42d+40L]) em parcelas subdivididas nos tempos $6,24,72 \mathrm{~h}$.

Adotando-se um D.I.C foi aplicado teste de médias para a degradação da MS, PB e FDN nos tempos de incubação, segundo metodologia recomendada por Sampaio (2002), utilizando-se o procedimento para Modelos Lineares Generalizados (PROC GLM) do logiciário estatístico SAS (2000).

\section{Resultados e Discussão}

Os resultados para degradação ruminal das dietas constituídas pelo feno de capim-Tifton 85 (FT) e leucena (FL), estão apresentados na Tabela 2.

As partículas que escapam à degradação (fração a) são degradadas em igual taxa que o alimento remanescente no saco, o que levaria à superestimativa da degradabilidade, tão maior quanto maior a fração a e menor a degradação do alimento remanescente no saco. Considerando-se que os potenciais de degradação da associação do feno de leucena (FL) e feno de capim-Tifton 85 processado aos 28 (FT28) e 42 (FT42) dias da rebrota apresentaram-se dentro dos limites preconizados para associações de gramíneas e leguminosas, as perdas por lavagem verificadas neste experimento possivelmente não comprometem as estimativas obtidas. 
SANTANA, Y.A.G. et al. Degradabilidade ruminal in situ de dietas volumosas para ruminantes constituídas pelos fenos de capim-tifton 85 e de leucena. PUBVET, Londrina, V. 6, N. 10, Ed. 197, Art. 1322, 2012.

Tabela 2 - Parâmetros de degradação, degradação potencial (DP) e degradação efetiva (DE) para as taxas de passagens 2,5 e $8 \% / h$, da matéria seca, proteína bruta e fibra em detergente neutro de dietas constituídas pelo feno de capim-Tifton 85 (FT) e leucena (FL)

\begin{tabular}{|c|c|c|c|c|c|c|c|}
\hline \multirow{3}{*}{ Parâmetros } & $\mathrm{FT2}$ & $8 d$ & $\mathrm{FT}$ & 42 & \multirow{3}{*}{ FL } & \multirow{3}{*}{ FT28d } & \multirow{3}{*}{$\mathrm{FT} 42 \mathrm{~d}$} \\
\hline & \multicolumn{4}{|c|}{ Níveis de FL (\%) } & & & \\
\hline & 20 & 40 & 20 & 40 & & & \\
\hline \multicolumn{8}{|c|}{ Matéria Seca } \\
\hline $\begin{array}{l}\text { Fração solúvel } \\
\text { (a, \% da MS) } \\
\text { Fração b (\% da MS)* }\end{array}$ & $\begin{array}{l}18,08 \\
63,75\end{array}$ & $\begin{array}{l}23,45 \\
52,51\end{array}$ & $\begin{array}{l}17,85 \\
57,56\end{array}$ & $\begin{array}{l}21,64 \\
48,66\end{array}$ & $\begin{array}{l}33,59 \\
32,59\end{array}$ & $\begin{array}{l}19,04 \\
60,74\end{array}$ & $\begin{array}{l}19,66 \\
59,85\end{array}$ \\
\hline $\begin{array}{c}\text { Taxa de degradação (c, } \\
\% \mathrm{~h}^{-1} \text { ) }\end{array}$ & 3,41 & 5,67 & 5,92 & 6,67 & 8,66 & 6,03 & 6,12 \\
\hline DP (\% da MS)* & 76,06 & 74,93 & 74,41 & 69,82 & 66,09 & 78,80 & 78,60 \\
\hline DE $(\%$ da MS $) *\left(2 \% h^{-1}\right)$ & 58,26 & 62,27 & 60,87 & 59,07 & 60,07 & 64,65 & 64,77 \\
\hline $\begin{array}{l}\left(5 \% h^{-1}\right) \\
\left(8 \% h^{-1}\right)\end{array}$ & $\begin{array}{l}43,93 \\
37,13\end{array}$ & $\begin{array}{l}51,35 \\
45,23\end{array}$ & $\begin{array}{l}49,05 \\
42,33\end{array}$ & $\begin{array}{l}49,45 \\
43,76\end{array}$ & $\begin{array}{l}54,25 \\
50,53\end{array}$ & $\begin{array}{l}52,25 \\
45,15\end{array}$ & $\begin{array}{l}52,60 \\
45,60\end{array}$ \\
\hline $\mathrm{R}^{2}$ & 92,56 & 97,35 & 98,72 & 97,25 & 96,42 & 97,86 & 98,32 \\
\hline \multicolumn{8}{|c|}{ Proteína Bruta } \\
\hline $\begin{array}{l}\text { Fração solúvel ( } a, \% \text { da } \\
\text { MS) }\end{array}$ & 27,10 & 33,82 & 37,50 & 37,78 & 44,76 & 37,81 & 31,46 \\
\hline Fração b (\% da MS)* & 71,54 & 55,29 & 53,03 & 44,72 & 42,40 & 50,65 & 49,89 \\
\hline $\begin{array}{c}\text { Taxa de degradação (c, } \\
\left.\qquad \mathrm{h}^{-1}\right)\end{array}$ & 2,28 & 4,31 & 3,81 & 5,29 & 6,62 & 5,01 & 4,20 \\
\hline DP (\% da MS)* & 85,97 & 86,22 & 86,53 & 81,37 & 86,77 & 79,59 & 85,55 \\
\hline DE $(\%$ da MS $) *\left(2 \% h^{-1}\right)$ & 65,21 & 71,59 & 72,28 & 70,23 & 77,32 & 67,12 & 72,12 \\
\hline $\begin{array}{r}\left(5 \% \mathrm{~h}^{-1}\right) \\
\left(8 \% \mathrm{~h}^{-1}\right)\end{array}$ & $\begin{array}{l}49,50 \\
42,96\end{array}$ & $\begin{array}{l}59,42 \\
53,18\end{array}$ & $\begin{array}{l}60,44 \\
54,61\end{array}$ & $\begin{array}{l}60,77 \\
55,58\end{array}$ & $\begin{array}{l}68,92 \\
63,96\end{array}$ & $\begin{array}{l}56,43 \\
50,67\end{array}$ & $\begin{array}{l}60,93 \\
55,25\end{array}$ \\
\hline $\mathrm{R}^{2}$ & 89,30 & 92,73 & 96,62 & 96,37 & 88,27 & 88,67 & 93,12 \\
\hline \multicolumn{8}{|c|}{ Fibra em detergente neutro } \\
\hline $\begin{array}{l}\text { Fração solúvel ( } a, \% \text { da } \\
\text { MS) }\end{array}$ & 12,65 & 19,46 & 13,28 & 17,73 & 28,17 & 16,88 & 15,58 \\
\hline Fração b (\% da MS)* & 69,81 & 53,34 & 62,68 & 51,35 & 29,03 & 60,09 & 57,43 \\
\hline $\begin{array}{c}\text { Taxa de degradação (c, } \\
\left.\qquad \mathrm{h}^{-1}\right)\end{array}$ & 2,81 & 4,92 & 5,07 & 6,06 & 6,31 & 6,70 & 5,38 \\
\hline $\mathrm{DP}(\%$ da MS)* & 73,03 & 70,94 & 73,96 & 68,28 & 56,85 & 73,56 & 75,45 \\
\hline DE $(\%$ da MS $) *\left(2 \% h^{-1}\right)$ & 53,43 & 57,38 & 58,23 & 56,37 & 50,21 & 59,81 & 60,66 \\
\hline$\left(5 \% h^{-1}\right)$ & 37,77 & 45,91 & 44,80 & 45,91 & 44,36 & 48,47 & 48,00 \\
\hline$\left(8 \% h^{-1}\right)$ & 30,80 & 39,77 & 37,59 & 39,90 & 40,97 & 41,75 & 41,01 \\
\hline $\mathrm{R}^{2}$ & 89,00 & 90,96 & 97,08 & 96,43 & 60,81 & 92,29 & 92,17 \\
\hline
\end{tabular}


SANTANA, Y.A.G. et al. Degradabilidade ruminal in situ de dietas volumosas para ruminantes constituídas pelos fenos de capim-tifton 85 e de leucena. PUBVET, Londrina, V. 6, N. 10, Ed. 197, Art. 1322, 2012.

A fração solúvel (fração a) da MS, PB e FDN tendeu a se elevar com o aumento do nível do feno de leucena com exceção da PB quando o feno de capim-Tifton 85 apresentou idade de rebrota de 42 dias (Tabela 2). Segundo Veloso (2006), estas diferenças na obtenção da fração a podem ocorrer, por influência, principalmente, do processo de lavagem aplicado em cada metodologia, pois a execução deste ainda não segue um padrão metodológico, o que pode resultar em perdas de partículas e, consequentemente, em superestimativas da degradabilidade.

O feno de capim-Tifton 85 com duas idades de rebrota $x$ Níveis do feno de leucena (20 e 40\% da MS) resultou em taxa de degradação de $c$ da MS superior a 3,0\%/h, dentro da faixa de 2,0 a $6,0 \% / \mathrm{h}$, considerada por Tomich e Sampaio (2004) ideal para volumosos de boa qualidade (Tabela 2).

A fração solúvel da FDN aumentou com nível de $40 \%$ feno de leucena, com grande participação da fração $b$, com taxa de degradação (c) superior a 2,0\%/h (Tabela 5). As dietas apresentaram fração potencialmente degradável (b) da FDN maiores que $45 \%$, inferior aos $75,0 \%$ obtido por Ítavo et al. (2002), no entanto, a degradação potencial $(A=a+b)$ da FDN de mais de $75 \%$ indica aproximação dos valores obtidos por Ítavo et al. (2002). Neste sentido, Tomich e Sampaio (2004) afirma que a idade da forrageira, o tratamento químico, bem como o tamanho da partícula, podem alterar o potencial de degradabilidade (A), mas não interferem na taxa de degradação (c).

O nível de $40 \%$ do feno de leucena resultou em menor $(P<0,05)$ degradação da MS e PB ( 74,93, 69,82 e 86,22, 81,37 respectivamente) que a obtida para o feno de leucena com $20 \%(76,06,74,41$ e 85,97, 86,53 respectivamente) (Tabela 5). Quanto à degradação da MS, Nouala et al. (2004) obtiveram $67,60 \%$ para feno de amendoim forrageiro incubado no rúmen por 96 h, e Carvalho et al. (2006) obtiveram, 71,07\% para feno de capim-colonião, $71,38 \%$ para feno de capim-Tifton e $73,00 \%$ para feno de capimbraquiária, incubados no rúmen por $72 \mathrm{~h}$. 
SANTANA, Y.A.G. et al. Degradabilidade ruminal in situ de dietas volumosas para ruminantes constituídas pelos fenos de capim-tifton 85 e de leucena. PUBVET, Londrina, V. 6, N. 10, Ed. 197, Art. 1322, 2012.

A degradação efetiva (DE) da MS, PB e FDN aumentou quando o capim tifton 85 com 28 dias de rebrota e $40 \%$ do feno de leucena e não aumentou com 42 dias de rebrota (Tabela 4). Com o aumento da taxa de passagem (2, 5 e $8 \% / h)$, a DE da MS, PB e FDN do feno de capim-Tiftn 85 sob diferentes níveis do feno de leucena, ou seja, quanto maior a taxa de passagem do alimento, menor a permanência no trato digestório e menor o tempo para a ação dos micro-organismos ruminais sobre as partículas do alimento, sendo o mesmo comportamento observado por Carvalho et al. (2006) para os fenos dos capins colonião, Tifton e braquiária.

A MS do feno de leucena apresentou-se muito solúvel (fração $a=33,59 \%$ ) e pouco degradável in situ (fração $b=32,59 \%$ ), no entanto, as estimativas de degradação potencial às taxas de passagem 2,5 e $8 \% \mathrm{~h}^{-1}$, para os níveis de consumo alimentar baixo, médio e alto, de 60,07; 54,25 e $50,53 \%$, respectivamente, indicam elevada degradação efetiva da MS do feno de leucena (Tabela 5). Estes resultados seguem a tendência apresentada para leguminosas arbóreas ricas em proteína bruta e carboidratos solúveis, concordando com resultados obtidos por Pires et al. (2006) para MS de feno de leucena, com taxas de passagem 2,5 e $8 \% h^{-1}$ de $62,9,53,9$ e $48,7 \%$ respectivamente. Destaca-se a elevada solubilidade (a) do feno de leucena, o que pode ser atribuído à grande riqueza em carboidratos não fibrosos e possivelmente de carboidratos solúveis.

A degradação efetiva da MS do feno de leucena, a uma taxa de passagem $5 \% \mathrm{~h}^{-1}(47,11 \%)$, foi igual à obtida por Veloso et al. (2000) para feno de leucena (Leucaena leucocephala (Lam.) De Wit.) $(47,80 \%)$ e maior para guandu $(19,25 \%)$. Embora o feno de leucena tenha apresentado elevada degradação potencial da MS, PB e FDN, a taxa de degradação da MS (c=6,62), Tabela 5, mostrou-se inferior à obtida por Pires et al. (2002) para feno de leucena $(c=7,22)$.

O valor de $A$, indicador do potencial máximo de degradação, obtido para a MS do feno de capim-tifton 85 com duas idades de rebrota $(28,42), 78,80$ e 
SANTANA, Y.A.G. et al. Degradabilidade ruminal in situ de dietas volumosas para ruminantes constituídas pelos fenos de capim-tifton 85 e de leucena. PUBVET, Londrina, V. 6, N. 10, Ed. 197, Art. 1322, 2012.

$78,60 \%$ respectivamente, encontra-se no intervalo de 65 a 95\%, recomendada por Tomich e Sampaio (2004) para fenos de gramíneas tropicais, enquanto a taxa de degradação c=6 mostra-se acima da estabelecida pelo autor, de 0,03 a 0,05 , denotando alta taxa de degradação. $O$ valor de $B$, indicador do potencial de degradação efetivamente devido à ação químico-microbiológica, 60,74 e $59,85 \%$ respectivamente, encontra-se dentro dos limites 55 a 85\%, preconizados por Tomich e Sampaio (2004), admitindo-se ainda valor de B 10 a $20 \%$ inferior ao valor de $A$, do que se depreende que as perdas de MS do feno de capim-tifton 85 por lavagem (fração $a=19,04$ e 19,66\% respectivamente), são aceitáveis para este alimento.

A fração a para PB do feno de capim-tifton 85 com duas idades de rebrota (28, 42 dias), 31,46 e 37,81\%, correspondente à proteína rapidamente degradada no rúmen (PRDR), segundo o AFRC (1993), indica maior solubilidade deste constituinte em relação à obtida por Alamouti et al. (2009), de 33,45\%, e por Ítavo et al. (2002), de 32,90\%. No entanto, a degradação efetiva para uma taxa de passagem $5 \% \mathrm{~h}^{-1}$, de 56,43 e $60,93 \%$ e próximo à obtida por Alamouti et al. (2009), de 56,02\% e Ítavo et al. (2002), de $55,09 \%$.

A fração solúvel da FDN diminuiu com a idade de rebrota 42 dias, com grande participação da fração $b$, com taxa de degradação (c) superior a 4,0\%/h, (Tabela 5). Taxa de degradação da FDN acima de 4,00\%/h também foi obtida por Carvalho et al. (2006) para fenos dos capins colonião, Tifton e braquiária.

A degradabilidade efetiva da MS, PB e FDN a $2 \% \mathrm{~h}^{-1}$, de 46,$71 ; 45,81$ e $43,77 \%$, respectivamente, reduziu em cerca de $30 \%$ quando se adotou taxa de passagem ( $5 \%$ h-1), correspondente ao nível de consumo médio, indicando a necessidade de maior permanência do feno de capim-tifton 85 no ambiente ruminal para se atingir seu máximo potencial de degradação, como sugerido por Ítavo et al. (2002). Verifica-se que os resultados apresentados na Tabela 6.4 aproximam-se dos obtidos por Ítavo et al. (2002) para degradabilidade 
SANTANA, Y.A.G. et al. Degradabilidade ruminal in situ de dietas volumosas para ruminantes constituídas pelos fenos de capim-tifton 85 e de leucena. PUBVET, Londrina, V. 6, N. 10, Ed. 197, Art. 1322, 2012.

efetiva da MS e FDN do feno de capim-tifton 85 a 2, 5 e $8 \%$ h-1, no entanto, a degradabilidade efetiva da PB para as respectivas taxas de passagem, 45,81; 30,39 e 25,05\%, apresentou-se muito abaixo da obtida pelos autores, de 67,$11 ; 55,09$ e 49,32\%. Apesar das amplas diferenças, segundo Van Soest (1994), há uma tendência de plantas cultivadas em regiões quentes apresentarem menor taxa de fermentação.

\section{Consideração Final}

A associação do feno do capim-Tifton com duas idades de rebrota e dois niveis do feno de leucena 20 e $40 \%$ promove aumento do teor de proteína bruta. $\mathrm{O}$ teor de PB, a degradabilidade in situ e a cinética de degradação da MS e PB são incrementados com $40 \%$ do feno de leucena.

\section{Referências Bibliográficas}

AGRICULTURAL AND FOOD RESEARCH COUNCIL (AFRC). Energy and ProteinRequirements of Ruminants. Wallingford, UK: CAB International, 1993. 159p.

ALAMOUTI, A. A. et al. Effects of lucerne particle size and source of dietary carbohydrates on in situ degradation and ruminal variables in sheep. Czech Journal Animal science, v.54, n.6, p.277-285, 2009.

CARVALHO, G.G.P. et al. Valor nutritivo do bagaço de cana-de-açúcar amonizado com quatro doses de uréia. Pesquisa Agropecuária Brasileira, v.41, n.1, p.125-132, 2006.

ÍTAVO, L.C.V. et al. Consumo, gênero Cynodon e rações concentradas utilizando indicadores internos. Revista Brasileira de Zootecnia, v.31, n.2, p.1024-1032, 2002.

LADEIRA, M.M. et al. Cinética ruminal do feno de Stylosanthes guianensis. Arquivo Brasileiro de Medicina Veterinária e Zootecnia, v.53, n.2, p.1-8, 2001.

LOPEZ, j.v; PETIT, A.R; NAVARRO, C; ATENCIO, C. Efecto de la Uplementación con Leucaena (Leucaena leucocephala LAM. DE WIT) Sobre la Degradabilidad Ruminal del Pasto Alemán (Echinochloa polystachya H.B.K. HITCH), FCV-LUZ, v.16, n.6, p.642-647, 2006.

NATIONAL RESEARCH COUNCIL (NRC). Ruminant Nitrogen Usage. Washington, D.C.: National Academy Press, 1985. 138p.

NOCEK, J. E. In situ and other methods to estimate ruminal protein and energy digestibility: A review. Journal of Dairy Science, v.71, n.3, p.2051-2069, 1988. 
NOUALA, F.S.; AKINBAMIJO, O.O.; SMITH, O.B.; PANDEY, V.S. Horticultural residues as ruminant feed in pri-urban area of the Gambia. Livestock Research for Rural

Development, v.16, n.6, p.1-6, 2004.

$\varnothing R S K O V$, E. R.; MCDONALD, I. The estimation of protein degradability in the rumen from incubation measurements weighted according to rate of passage. Journal of Agricultural Science, v.92, n.2, p.499-503, 1979.

PEREZ, S.C.J.G.A; FANTI, S.C. Crescimento e Resistência à Seca de Leucena em Solo de Cerrado. Pesquisa Agropecuaria Brasileira, v.34, n.6, p.933-944, 1999.

PIRES, A.J.V. et al. Degradabilidade ruminal da matéria seca, da fração fibrosa e da proteína bruta de forrageiras. Pesquisa Agropecuaria Brasileira, v.41, n.4, p.643-648, 2006.

SAMPAIO, I. B. M. Estatística Aplicada à Experimentação Animal. 2.ed. Belo Horizonte: Fundação de Ensino e Pesquisa em Medicina Veterinária e Zootecnia, 2002. 265 p.

SAMPAIO, I.B.M.; PIKE, D.J.; OWEN, E. Optimal design for studying dry matter degradation in the rumen. Arquivos Brasileiros de Medicina Veterinária e Zootecnia. v.47, n.3, p.373383, 1995.

SAMPAIO, I.B.M. Experimental designs and modeling techniques in the study of roughage degradation in rumen and growth of ruminants. Reading: University of Reading, 1988. 214p. Tese (Doctor in Physiology) - University of Reading, 1988.

STATISTICAL ANALYSIS SYSTEM. SAS. User's Guide. Statistics Version 8. SAS Institute Inc., Cary, NC, USA, 2000.

TOMICH, T.R.; SAMPAIO, I.B.M. A new strategy for the determination of forage degradability with an in situ technique through the use of one fistulated ruminant. Journal of Agricultural Science, v.142, p.589-593, 2004.

TONANI, F.L. et al. Degradabilidade ruminal in situ da matéria seca e da fibra em detergente neutro em silagens de híbridos de sorgo colhidos em diferentes épocas. Arquivo Brasileiro de Medicina Veterinária e Zootecnia, v.53, n.1, p.100-104, 2001.

UDEN, P., VAN SOEST, P.J. Investigation of the in situ bag technique and a comparison of the fermentation in heifers, sheep, ponies, and rabbits. Journal of Animal Science, 58, 213$221,1984$.

VAN SOEST, P.J. Nutritional Ecology of the Ruminant. 2th ed. Ithaca, New York: Cornell University Press, 1994. 476p.

VELOSO, C. M. et al Degradabilidade ruminal da matéria seca e da proteína bruta de folhas e folíolos de forrageiras tropicais. Revista Brasileira de Zootecnia. v.35, n.2, p.613-617, 2006.

VELOSO, C.M. et al. pH e amônia ruminais, relação folhas: hastes e degradabilidade ruminal da fibra de forrageiras tropicais. Revista Brasileira de Zootecnia, v.29, n.3, p.871-879, 2000. 